Original Article

\title{
Nicotinamide phosphoribosyltransferase regulates the cell differentiation and mineralization in cultured odontoblasts
}

\author{
Kyeong-Rok Kang1', Jae-Sung Kim ${ }^{1}$, Jeong-Yeon Seo ${ }^{1,2}$, Hyangl Lim', Tae-Hyeon Kim', Sun-Kyoung Yu', \\ Heung-Joong Kim', Chun Sung Kim', Hong Sung Chun², Joo-Cheol Park', and Do Kyung Kim ${ }^{1, *}$ \\ ${ }^{1} T$ The Institute of Dental Science, Chosun University, ${ }^{2}$ Department of Integrative Biological Sciences \& BK21 FOUR Educational Research Group for Age- \\ associated Disorder Control Technology, Chosun University, Gwangju 61452, ${ }^{3}$ Laboratory for the Study of Regenerative Dental Medicine, Department of Oral \\ Histology-Developmental Biology, School of Dentistry and Dental Research Institute, Seoul National University, Seoul 08826, Korea
}

\section{ARTICLE INFO}

Received October 13, 2021

Revised November 16, 2021

Accepted November 23, 2021

*Correspondence

Do Kyung Kim

E-mail:kdk@chosun.ac.kr

Key Words

Differentiation

Nicotinamide phosphoribosyltransferase

Odontoblasts

Tooth development
ABSTRACT The aim of the present study was to investigate the physiological role of nicotinamide phosphoribosyltransferase (NAMPT) associated with odontogenic differentiation during tooth development in mice. Mouse dental papilla cell-23 (MDPC23) cells cultured in differentiation media were stimulated with the specific NAMPT inhibitor, FK866, and Visfatin (NAMPT) for up to 10 days. The cells were evaluated after $0,4,7$, and 10 days. Cell viability was measured using the 3-(4,5-dimethylthiazol-2-yl)-2,5-diphenyltetrazolium bromide assay. The mineralization assay was performed by staining MDPC-23 cells with Alizarin Red S solution. After cultivation, MDPC-23 cells were harvested for quantitative PCR or Western blotting. Analysis of variance was performed using StatView 5.0 software (SAS Institute Inc., Cary, NC, USA). Statistical significance was set at $p<0.05$. The expression of NAMPT increased during the differentiation of murine odontoblast-like MDPC-23 cells. Furthermore, the up-regulation of NAMPT promoted odontogenic differentiation and accelerated mineralization through an increase in representative odontoblastic biomarkers, such as dentin sialophosphoprotein, dentin matrix protein-1, and alkaline phosphatase in MDPC-23 cells. However, treatment of the cells with the NAMPT inhibitor, FK866, attenuated odontogenic differentiation, as evidenced by the suppression of odontoblastic biomarkers. These data indicate that NAMPT regulated odontoblastic differentiation through the regulation of odontoblastic biomarkers. The increase in NAMPT expression in odontoblasts was closely related to the formation of the extracellular matrix and dentin via the Runx signaling pathway. Therefore, these data suggest that NAMPT is a critical regulator of odontoblast differentiation during tooth development.

\section{INTRODUCTION}

Tooth formation occurs via a precise developmental process, regulated by epithelial-mesenchymal interactions between the odontogenic epithelium and ectodermal mesenchymal cells [1]. The odontogenic epithelium forms a dental organ that secretes enamel proteins, whereas the ectodermal mesenchymal cells form a dental papilla, which differentiates into odontoblasts and pulp cells that in turn give rise to the crown dentin and pulp $[2,3]$. After the crown formation is completed, the inner and outer tooth epithelium proliferate under the crown to form the Hertwig epithelial root sheath, which determines the shape of the tooth root and induces the differentiation of odontoblasts to form the root dentin $[2,4]$. Dentin is the most important component of teeth

\section{(i) (8)}

This is an Open Access article distributed under the terms of the Creative Commons Attribution Non-Commercial License, which permits unrestricted non-commercial use, distribution, and reproduction in any medium, provided the original work is properly cited. Copyright $\odot$ Korean J Physiol Pharmacol, pISSN 1226-4512, elSSN 2093-3827
Author contributions: K.R.K., J.Y.S., H.I.L., T.H.K., and D.K.K. contributed to the cell based experimental design and collected the data. J.S.K., S.K.Y., H.J.K., C.S.K., H.S.C., J.C.P., and J.S.K. contributed to the data analysis and interpretation. K.R.K. and D.K.K. did the writing and revisions of manuscript. 
and constitutes most of the crown and root $[5,6]$. Odontoblast differentiation is a highly organized and complex process involving various cytoplasmic molecules, signal transmitters, growth factors, ions, and receptors [7-9]. Transforming growth factor- $\beta$ and dentin matrix protein-1 (DMP-1) are known to be involved in odontoblast differentiation. However, these factors are generally involved in the formation of various hard tissues, and are not selectively involved in dentinal blast cell differentiation [10,11]. In addition, it has been shown that knockout of the dentin sialophosphoprotein (DSPP) gene is associated with failure of calcific microspheres to fuse during dentin calcification, enlargement of the pulp chamber, widening of the predentin zone, decreased calcification, and pulp exposure. Even in such a scenario, the differentiation and maturation of odontoblasts proceed normally, indicating that DSPP is not the only factor regulating the differentiation of odontoblasts [12]. Despite these studies, the biomolecular mechanisms related to the odontoblast differentiation and dentin formation have not yet been clearly elucidated. Recently, increased interest in dentin regeneration has prompted numerous studies, but much of the data are insignificant due to the specificity of dentin and various experimental limitations [13]. To address these issues, the development of dentin regeneration inducers using molecular biology, bioengineering, and tissue engineering is considered a major priority in future dentin regeneration research [13]. Therefore, a clear understanding of the differentiation mechanism of odontoblasts is essential.

Nicotinamide phosphoribosyltransferase (NAMPT), also known as Visfatin and pre-B cell colony-enhancing factor, is the rate-limiting enzyme in the mammalian salvage pathway for $\mathrm{NAD}^{+}$biosynthesis from nicotinamide [14]. The intracellular levels of $\mathrm{NAD}^{+}$and nicotinamide have recently been linked to osteogenesis, suggesting a possible mechanism for the development of senile osteoporosis [15]. Recently, a study on the effects of NAMPT on osteoblast differentiation was also reported [16]. However, little data have been reported on the effects of NAMPT on odontoblast differentiation and dentin formation.

The MDPC-23 cell line, widely used in the study of odontoblasts, is derived from the healing head of a CD-1 mouse molar [17-19]. Therefore, we investigated the molecular mechanism by which NAMPT regulates odontoblast differentiation in MDPC23 odontoblastic cells, derived from mouse dental papilla cells.

\section{METHODS}

\section{Cell culture}

MDPC-23 odontoblast-like cells were supplied by Dr. J. E. Nör (University of Michigan, Ann Arbor, MI, USA) and cultured at $37^{\circ} \mathrm{C}$ in Dulbecco's modified Eagle's medium (DMEM; Welgene, Daegu, Korea), supplemented with $10 \%$ fetal bovine serum (FBS; Welgene) and penicillin (100 U/ml)-streptomycin $(100 \mu \mathrm{g} / \mathrm{ml})$ in a
5\% $\mathrm{CO}_{2}$-humidified atmosphere. Furthermore, $50 \mu \mathrm{g} / \mathrm{ml}$ ascorbic acid and $10 \mathrm{mM} \beta$-glycerophosphate were added for cell differentiation.

\section{Cell viability test}

MDPC-23 cells were seeded at a concentration of $2 \times 10^{4}$ cells per well in 48 -well plates. After $24 \mathrm{~h}$ of growth at $37^{\circ} \mathrm{C}$, the cells were treated with specific NAMPT inhibitors, FK866 (Santa Cruz Biotechnology Inc., Dallas, TX, USA) or Visfatin (Sigma-Aldrich, St. Louis, MO, USA) at various concentrations for $24 \mathrm{~h}$ and 48 $h$, respectively, after which cell viability was assessed using the 3-(4,5-dimethylthiazol-2-yl)-2,5-diphenyltetrazolium bromide (MTT; Sigma-Aldrich) colorimetric assay. At least three separate experiments were performed for each concentration combination.

\section{Alizarin Red S staining}

The MDPC-23 cells were fixed with 70\% ethanol for $30 \mathrm{~min}$, and stained with $1 \%$ alizarin Red S (Sigma-Aldrich) in $0.1 \%$ $\mathrm{NH} 4 \mathrm{OH}$ at $\mathrm{pH}$ 4.2-4.4. Mineralization assays were performed by staining MDPC-23 cells with alizarin Red S solution. The cells were evaluated at $0,4,7$, and 10 days. To quantify the intensity of mineralization, the density of stained nodules was measured using colorimetric spectrophotometry. The stained cells were collected by centrifugation at $10,500 \mathrm{~g}$ for $15 \mathrm{~min}$ at $4^{\circ} \mathrm{C}$. The cells were solubilized with $5 \%$ sodium dodecyl sulfate (SDS; $0.5 \mathrm{ml}$ ) in $0.5 \mathrm{~N} \mathrm{HCl}$ for $30 \mathrm{~min}$ at $23^{\circ} \mathrm{C}$. An aliquot of $200 \mu \mathrm{l}$ of the solubilized solution was transferred to a 96 -well plate, and the absorbance was measured at $405 \mathrm{~nm}$ using a spectrophotometer.

\section{Quantitative PCR and quantitative real time-PCR}

To perform quantitative PCR (qPCR), total RNA was isolated from MDPC-23 cells using TRIzol reagent (Invitrogen, Carlsbad, CA, USA) according to the manufacturer's instructions. The total RNA concentration was measured using a NanoDrop 2000 spectrophotometer (Thermo Scientific, Rockford, IL, USA). To synthesize cDNA, $1 \mu \mathrm{g}$ RNA was reverse-transcribed using a ThermoScript reverse transcription-PCR system (Invitrogen) according to the manufacturer's instructions. qPCR of cDNA was performed using $2 \times$ TOPsimple DyeMIX-nTaq (Enzynomics, Seoul, Korea) and specific primers on a TaKaRa PCR Thermal Cycler Device (TaKaRa Bio Inc., Shiga, Japan). Thereafter, the PCR products were electrophoresed on agarose gel to determine the expression levels of the target genes. Glyceraldehyde 3-phosphate dehydrogenase (GAPDH) was used as an endogenous control. In addition, cDNA was amplified for quantitative real timePCR (qRT-PCR) using an Eco Real-Time PCR system (Illumina Inc., San Diego, CA, USA). GAPDH was used as an endogenous control. The sequences of the primers used in qPCR and qRTPCR are summarized in Tables 1 and 2, respectively. 
Table 1. Quantitative PCR primer sequences used in this study

\begin{tabular}{|c|c|c|}
\hline Gene & Sequence $\left(5^{\prime}-3^{\prime}\right)$ & NCBI gene No. \\
\hline \multirow[t]{2}{*}{ NAMPT } & Forward: GAAGTACAGAGGCACCACTAATC & NM_021524.2 \\
\hline & Reverse: TCAGCAACTGGGTCCTTAAAC & \\
\hline \multirow[t]{2}{*}{$B S P$} & Forward: GAAGGCTGGAGATGCAGAAA & NM_008318.3 \\
\hline & Reverse: CATCCTCATAAGCTCGGTAAGTG & \\
\hline \multirow[t]{2}{*}{$D M P-1$} & Forward: CTGTCATTCTCCTTGTGTTCCT & NM_001359013.1 \\
\hline & Reverse: GTCGTCTTCATCATCCTCCTTATC & \\
\hline \multirow[t]{2}{*}{$D S P P$} & Forward: GAAGAGCCAAGATCAGGGAATAG & NM_010080.3 \\
\hline & Reverse: CACTTTCGTCACTTCCGTTAGA & \\
\hline \multirow[t]{2}{*}{$A L P$} & Forward: GGCCTGGATCTCATCAGTATT & NM_007431.3 \\
\hline & Reverse: CCACAGTCAAGGTGTCTTTCT & \\
\hline \multirow[t]{2}{*}{$\mathrm{Col}-1$} & Forward: GCCAAGAAGACATCCCTGAA & NM_007742.4 \\
\hline & Reverse: AGGACATCTGGGAAGCAAAG & \\
\hline \multirow[t]{2}{*}{ GAPDH } & Forward: GGGTGTGAACCACGAGAAATA & NM_001289726.1 \\
\hline & Reverse: GTTGAAGTCGCAGGAGACAA & \\
\hline
\end{tabular}

NCBI, National Center for Biotechnology Information; NAMPT, nicotinamide phosphoribosyltransferase; BSP, bone sialoprotein; DMP-1, dentin matrix protein-1; DSPP, dentin sialophosphoprotein; ALP, alkaline phosphatase; Col-1, collagen type-1; GAPDH, glyceraldehyde 3-phosphate dehydrogenase.

Table 2. Quantitative real-time PCR primer sequences used in this study

\begin{tabular}{|c|c|c|}
\hline Gene & Sequence $\left(5^{\prime}-3^{\prime}\right)$ & NCBI gene No. \\
\hline \multirow[t]{2}{*}{ NAMPT } & Forward: CAGAGCACAGTACCATAACGG & NM_021524.2 \\
\hline & Reverse: TCACСССАТАТTTТСТСАCACG & \\
\hline \multirow[t]{2}{*}{$B S P$} & Forward: CТССАСАСТТТССАСАСТСТС & NM_008318.3 \\
\hline & Reverse: GTCGСTTTCСTTCACTTTTGG & \\
\hline \multirow[t]{2}{*}{$D M P-1$} & Forward: CTCAAGAAAACAGTGCCCAAG & NM_001359013.1 \\
\hline & Reverse: СТGTTССТСАСТСТСАСТGTC & \\
\hline \multirow[t]{2}{*}{$D S P P$} & Forward: AGTAATGGTGATGGTGACAGTG & NM_010080.3 \\
\hline & Reverse: GTCAGATTCGTCСTTGTCСТC & \\
\hline \multirow[t]{2}{*}{$A L P$} & Forward: CTCCAAAAGCTCAACACCAATG & NM_007431.3 \\
\hline & Reverse: ATTTGTCСАTCTCCAGCCG & \\
\hline \multirow[t]{2}{*}{$\mathrm{Col}-1$} & Forward: CTCCCAGAACATCACCTATCAC & NM_007742.4 \\
\hline & Reverse: TGTAGGTGAAGCGACTGTTG & \\
\hline \multirow[t]{2}{*}{ GAPDH } & Forward: CCACTCACGGCAAATTCAAC & M_001289726.1 \\
\hline & Reverse: СТCCACGACATACTCAGCAC & \\
\hline
\end{tabular}

NCBI, National Center for Biotechnology Information; NAMPT, nicotinamide phosphoribosyltransferase; BSP, bone sialoprotein; DMP-1, dentin matrix protein-1; DSPP, dentin sialophosphoprotein; ALP, alkaline phosphatase; Col-1, collagen type-1; GAPDH, glyceraldehyde 3-phosphate dehydrogenase.

\section{Immunoblotting}

Protein extraction was performed to determine the level of odontoblastic biomarkers in the MDPC-23 cells. The concentration of total protein extracted from primary rat chondrocytes was determined using a bicinchoninic acid protein assay kit (Thermo Scientific) according to the manufacturer's instructions. Equal amounts of proteins were loaded onto a SDS-polyacrylamide gel electrophoresis (SDS-PAGE) system, and subsequently transferred onto nitrocellulose membranes. Immunoblotting was performed using primary antibodies against DSPP (1:1,000), NAMPT (1:1,000), bone sialoprotein (BSP, 1:1,000), Runx-1 (1:1,000), Runx2 (1:1,000), Runx-3 (1:1,000), and $\beta$-actin $(1: 2,500)$, all purchased from Santa Cruz Biotechnology, as well as primary antibody against DMP-1 (1:1,000; Thermo Scientific). Immunoreactive bands were visualized using an enhanced chemiluminescence system (Thermo Scientific) according to the manufacturer's instructions, and then imaged using a Microchemi device (DNR Bioimaging Systems, Jerusalem, Israel).

\section{Statistical analysis}

All experiments were performed at least in triplicate. The results are presented as mean \pm SEM. Statistical significance was analyzed using Student's t-test for two groups and one-way analysis of variance for multi-group comparisons. All statistical analy- 
ses were performed using SPSS (version 12.0; SPSS Inc., Chicago, IL, USA). Statistical significance was set at $\mathrm{p}<0.05$.

\section{RESULTS}

\section{NAMPT expression was up-regulated during cell differentiation of MDPC-23 odontoblastic-like cells}

To confirm the change in the expression level of NAMPT during the differentiation of MDPC-23 odontoblasts, ascorbic acid (50 $\mu \mathrm{l} / \mathrm{ml})$ and $\beta$-glycerophosphate $(10 \mathrm{mM})$ were added to MDPC23 cells and differentiation was induced. The degree of mineralized nodules showed a tendency to increase from day 4 of culture in the differentiation induction medium, and it was confirmed that the number of mineralized nodules increased as time passed from day 7 to day 10 (Fig. 1A). To confirm whether MDPC-23 cells were differentiated, the expression of odontoblast differen- tiation biomarkers during cell line differentiation was confirmed using qPCR analysis. The qPCR results showed that BSP mRNA expression, a biomarker of osteoblast differentiation, was not detected. On the other hand, expression of alkaline phosphatase $(A L P)$, Col-1, DMP-1, and DSPP mRNA, which are biomarkers of odontoblast differentiation, increased over time from day 4 to day 10 in the differentiation process of MDPC-23 cells. In addition, the expression of NAMPT mRNA increased in a time-dependent manner (Fig. 1B). These results show that NAMPT was significantly up-regulated during MDPC-23 cell differentiation.

\section{NAMPT increased mineralization in MDPC-23 odontoblasts}

An MTT assay was performed to determine the concentration of Visfatin that does not affect the proliferation of MDPC-23 cells, and an appropriate concentration of $50 \mathrm{ng} / \mathrm{ml}$ was calculated (Fig. $2 \mathrm{~A})$. As a result of treating MDPC-23 cells with $50 \mathrm{ng} / \mathrm{ml}$ Visfatin,
A
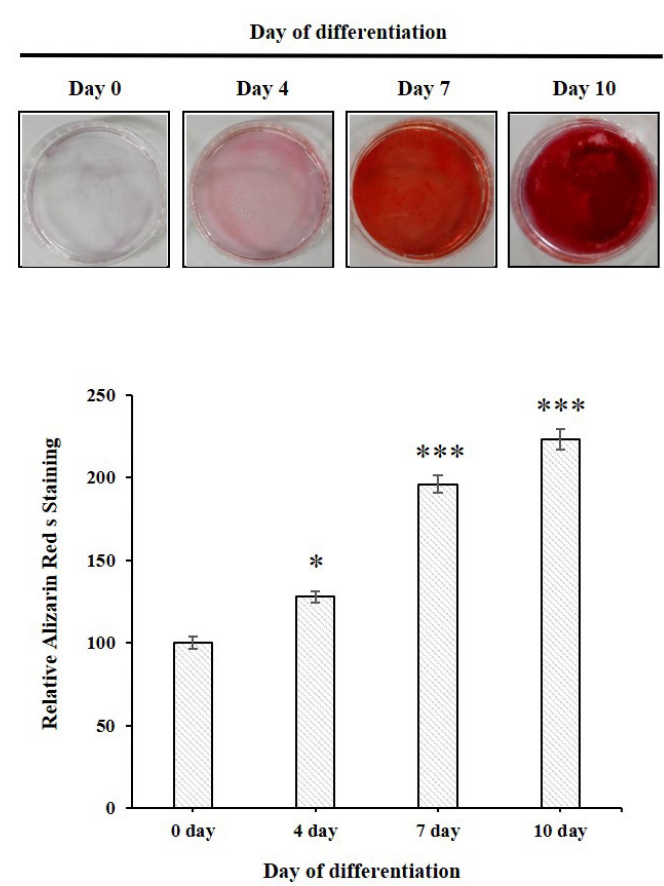

B
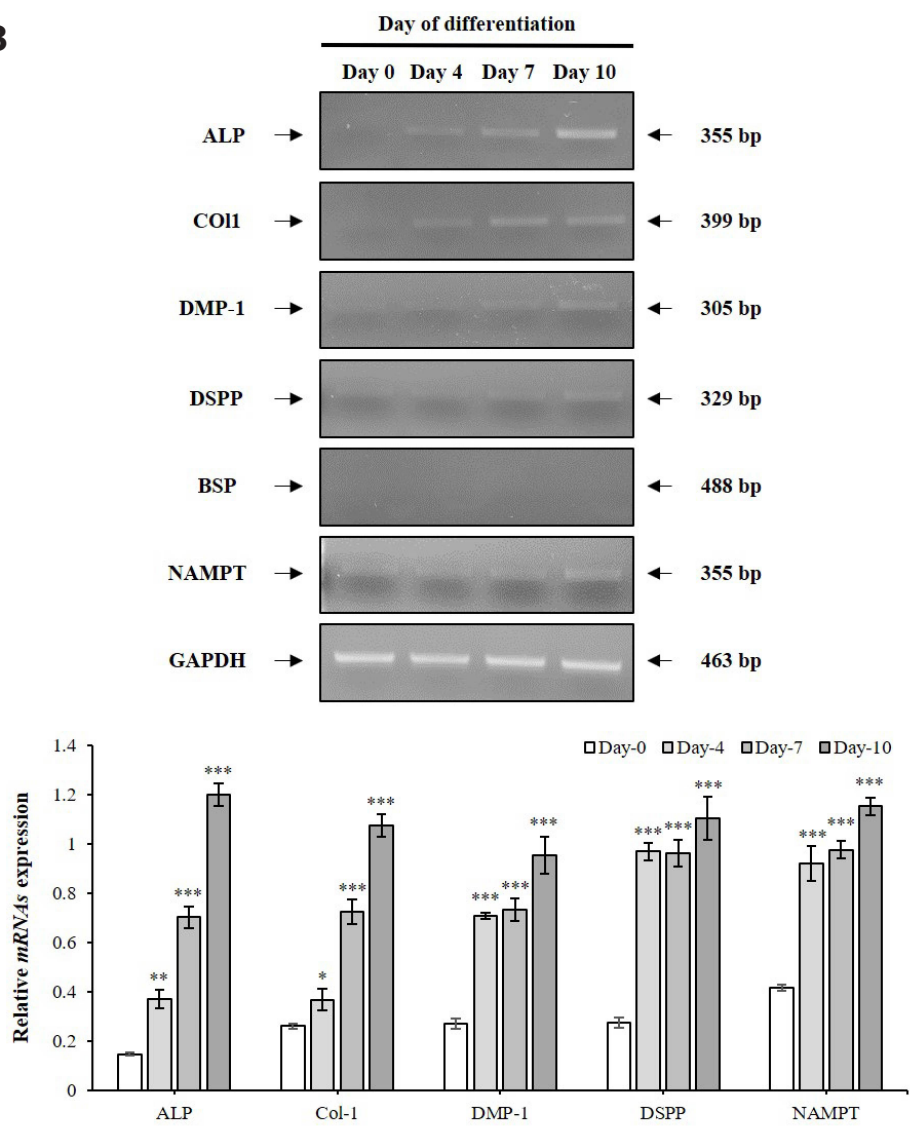

Fig. 1. The expression of NAMPT during odontoblastic differentiation of MDPC-23 cells. (A) Mineralized nodule formation in MDPC-23 cells. MDPC-23 cells were cultured with odontoblastic induction medium for 10 days, and mineralization was evaluated by alizarin Red S staining (upper panel). The mineralization was quantified by colorimetric spectrophotometry (lower panel). (B) mRNAs were prepared on day $0,4,7$, and 10 after induction. $\mathrm{qPCR}$ was performed to detect the expression levels of $A L P, C O \mathrm{l}-1, D M P-1, D S P P, B S P$, and NAMPT. Quantitative data for mRNA expressions (B, upper panel) were analyzed by using ImageJ software after GAPDH normalization ( $\mathrm{B}$, lower panel). Each data point represents the mean $\pm \mathrm{SEM}$ of three experiments. NAMPT, nicotinamide phosphoribosyltransferase; MDPC-23, mouse dental papilla cell-23; BSP, bone sialoprotein; DMP-1, dentin matrix protein-1; DSPP, dentin sialophosphoprotein; ALP, alkaline phosphatase; Col-1, collagen type-1; GAPDH, glyceraldehyde 3-phosphate dehydrogenase. ${ }^{*} \mathrm{p}<0.05,{ }^{* *} \mathrm{p}<0.01,{ }^{* * *} \mathrm{p}<0.001$. 
A
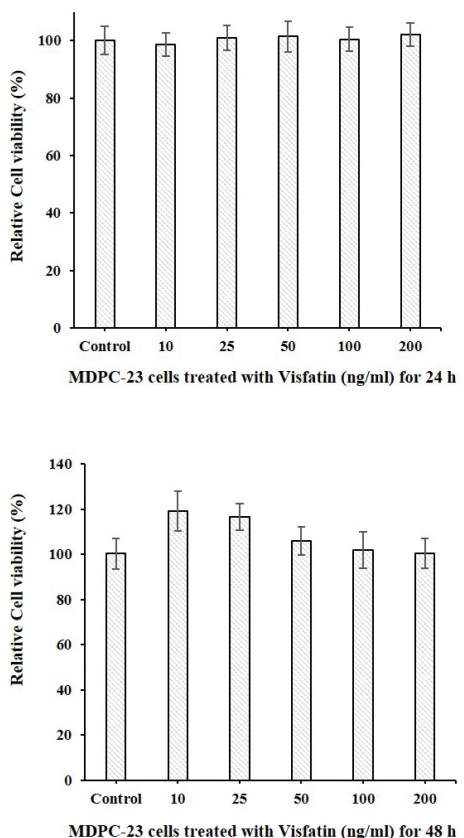
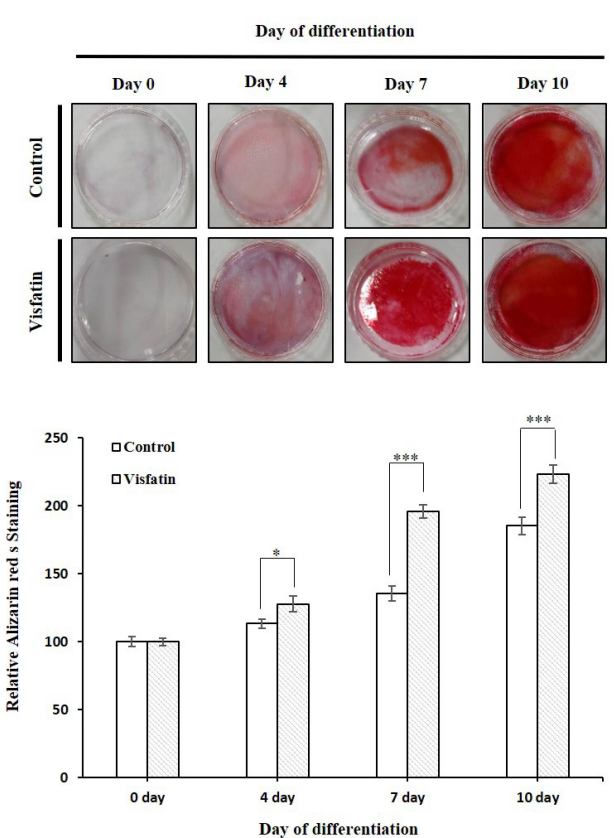

C

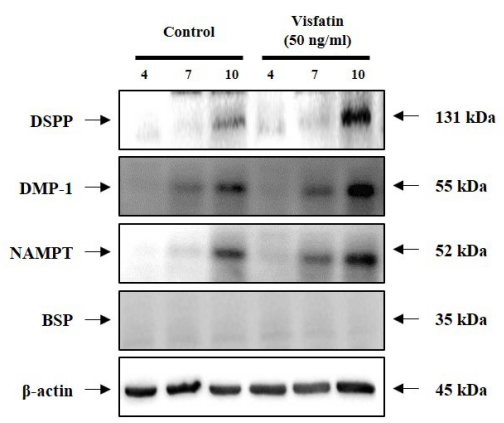

Fig. 2. The effects of Visfatin on mineralization in MDPC-23 cells. (A) MDPC-23 cell viability after Visfatin treatment as determined by MTT assays. (B) Alizarin Red S stain (upper panel) showing mineralized nodule formation in MDPC-23 cells, cultured in differentiation media and treated with Visfatin for up to 10 days. The mineralization was quantified using colorimetric spectrophotometry (lower panel). (C) Treatment with Visfatin at $50 \mathrm{ng} / \mathrm{ml}$ according to the defined conditions. The expression level of odontoblast biomarkers were assayed by Western blotting according to standard methods. Quantitative data for protein expressions ( $C$, upper panel) were analyzed by using ImageJ software after $\beta$-actin normalization (C, lower panel). Each data point represents the mean \pm SEM of three experiments. MDPC-23, mouse dental papilla cell-23; DSPP, dentin sialophosphoprotein; DMP-1, dentin matrix protein-1; NAMPT, nicotinamide phosphoribosyltransferase; BSP, bone sialoprotein. ${ }^{*} \mathrm{p}<0.05,{ }^{* *} \mathrm{p}<0.01,{ }^{* * *} \mathrm{p}<0.001$.

the number of mineralized nodules was increased in the Visfatintreated group compared with the control group at day 4, day 7 , and day 10. A clear increase in mineralized nodules was observed (Fig. 2B). Western blotting was performed to evaluate changes in the expression of the odontoblast differentiation biomarkers. The expression of DSPP, DMP-1, and NAMPT was increased in a time-dependent manner at day 4 , day 7 , and day 10 , respectively, in the Visfatin-treated group, but protein expression of the osteoblast differentiation marker, BSP, was not observed (Fig. 2C). These results indicate that NAMPT promoted MDPC-23 cell differentiation.

\section{NAMPT inhibitor FK866 decreased odontoblast formation in MDPC-23 odontoblasts}

The results of the MTT assay indicated $1 \mathrm{nM}$ as the concentration of FK866 that did not affect the proliferation of the MDPC-23 cells (Fig. 3A). Alizarin Red S staining of the cells was performed after treatment with FK866, a NAMPT inhibitor, to evaluate the effect of NAMPT inhibition on MDPC-23 cell differentiation. From day 4 of incubation, mineralized nodules tended to decrease in the FK866 treatment group compared with the control group, and on day 7 and day 10 of incubation, a marked decrease in mineralized nodules was observed in the FK866 treat- ment group compared with the control group (Fig. 3B). Furthermore, qRT-PCR confirmed that FK866 treatment suppressed the gene expression of NAMPT in MDPC-23 cell differentiation. In addition, the expression of ALP, Col-1, DMP-1, and DSPP mRNA, which are markers of odontoblast differentiation, decreased over time from day 4 to day 10 of the MDPC-23 cell differentiation process; there was no difference in the mRNA expression level of the osteoblast differentiation biomarker, BSP (Fig. 4A-F). Furthermore, when the cells were treated with FK866, the protein expression of NAMPT was suppressed. In addition, the expression of DMP-1 and DSPP proteins, which are markers of odontoblast differentiation, decreased over time from day 4 to day 10 in the MDPC-23 cell differentiation process, but there was no change in BSP protein expression (Fig. 4G). These data suggest that FK866 inhibited MDPC-23 cell differentiation.

\section{NAMPT regulates the Runx signal during MDPC-23 odontoblast differentiation}

In order to confirm whether NAMPT regulates the Runx signal during the differentiation process of MDPC- 23 cells, western blot was performed. The expression of Runx-1, Runx-2, and Runx-3 decreased when FK866 was applied during MDPC-23 cell differentiation (Fig. 5A). Conversely, the expression of Runx- 
A
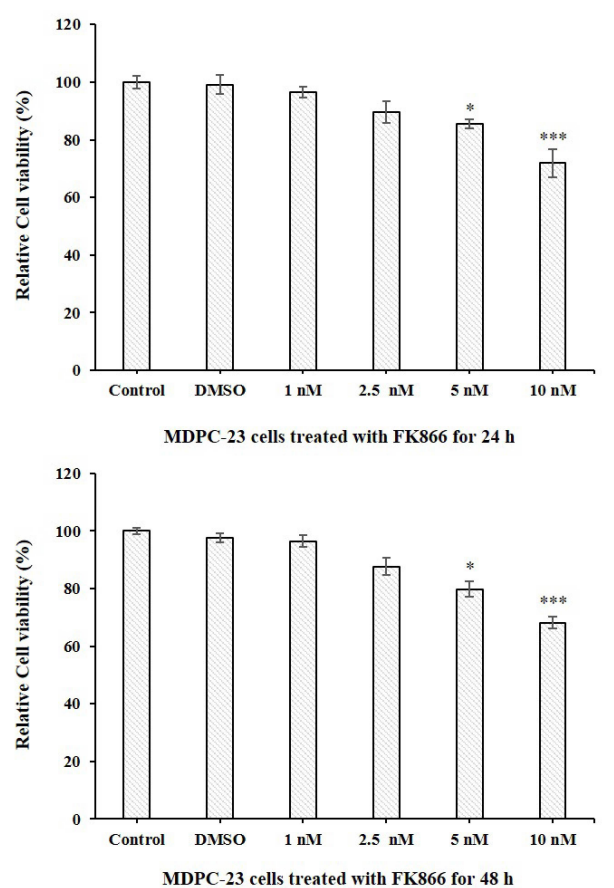

B

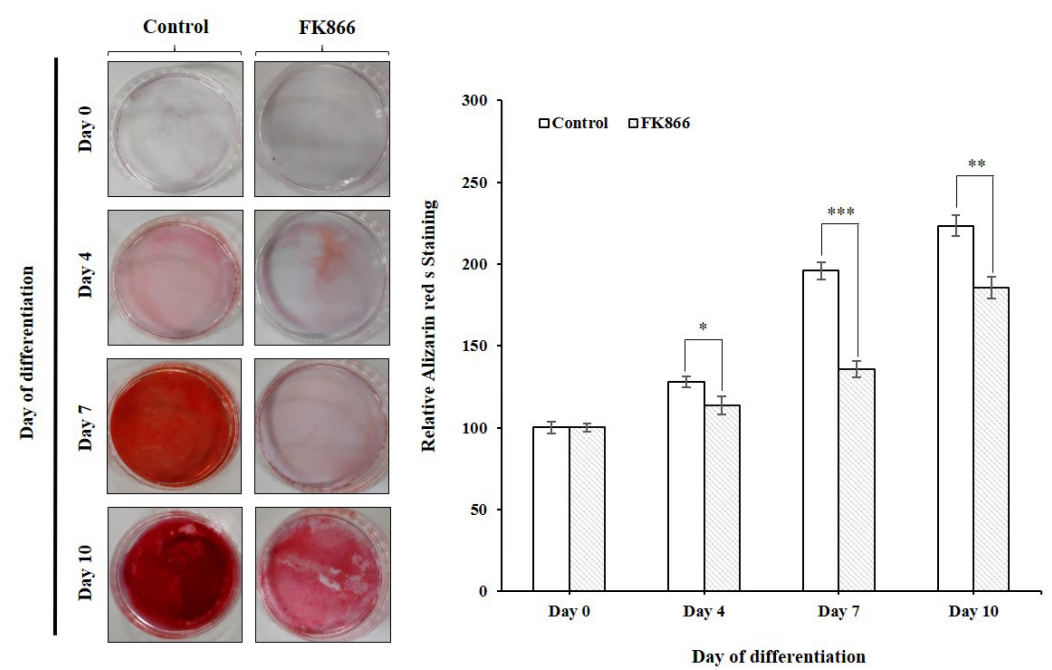

Fig. 3. The effects of the specific NAMPT inhibitor, FK866, on mineralization in MDPC-23 cells. (A) MDPC-23 cell viability after FK866 treatment as determined by MTT assays. (B) Alizarin Red S stain (left panel) showing mineralized nodule formation in MDPC-23 cells, cultured in differentiation media and treated with FK866 for up to 10 days. The mineralization was quantified using colorimetric spectrophotometry (right panel). Each data point represents the mean \pm SEM of three experiments. NAMPT, nicotinamide phosphoribosyltransferase; MDPC-23, mouse dental papilla cell-23. ${ }^{*} p<0.05$, ${ }^{* *} p<0.01,{ }^{* * *} p<0.001$.

A

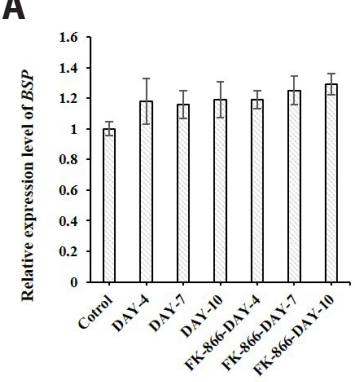

E

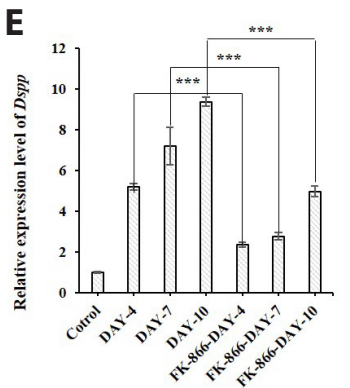

B

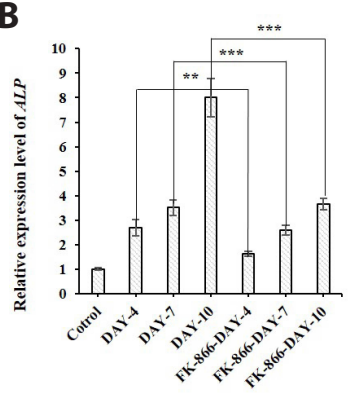

$\mathbf{F}$

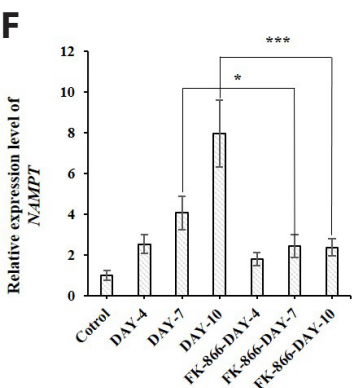

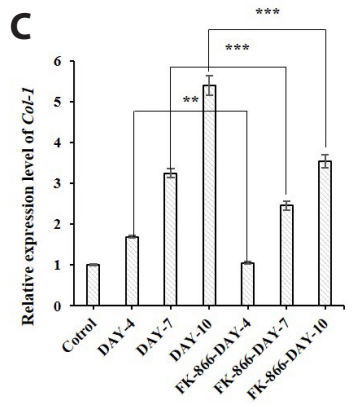

G

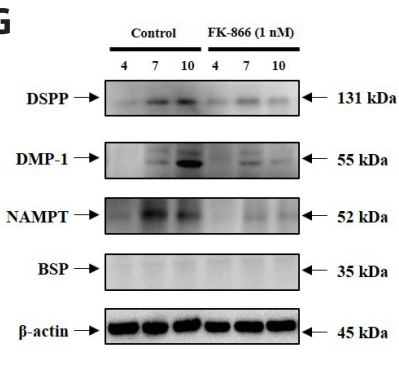

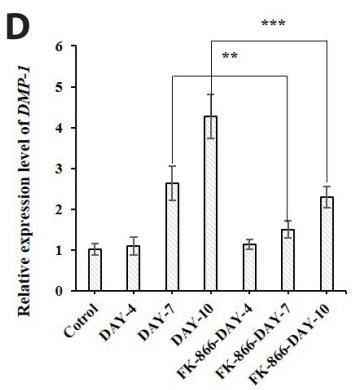

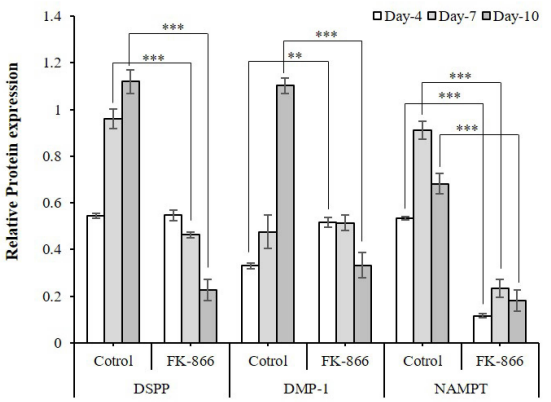

Fig. 4. The role of the specific NAMPT inhibitor, FK866, on differentiation in MDPC-23. qRT-PCR was performed to detect the expression levels of BSP (A), ALP (B), Col-1 (C), DMP-1 (D), DSPP (E), and NAMPT (F). GAPDH served as the experimental control. All data are based on three independent experiments. (G) Treatment with FK866 at $1 \mathrm{nM}$ according to the defined conditions. Western blotting was used to assess the expression level of odontoblast biomarkers. Quantitative data for protein expressions ( $G$, left panel) were analyzed by using ImageJ software after $\beta$-actin normalization (G, right panel). Each data point represents the mean \pm SEM of three experiments. MDPC-23, mouse dental papilla cell-23; BSP, bone sialoprotein; ALP, alkaline phosphatase; Col-1, collagen type-1; DMP-1, dentin matrix protein-1; DSPP, dentin sialophosphoprotein; NAMPT, nicotinamide phosphoribosyltransferase; GAPDH, glyceraldehyde 3-phosphate dehydrogenase. ${ }^{*} p<0.05,{ }^{* *} p<0.01,{ }^{* * *} p<0.001$. 
A

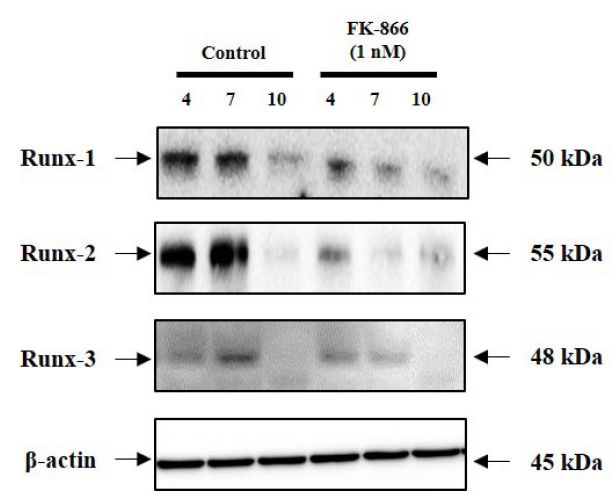

B

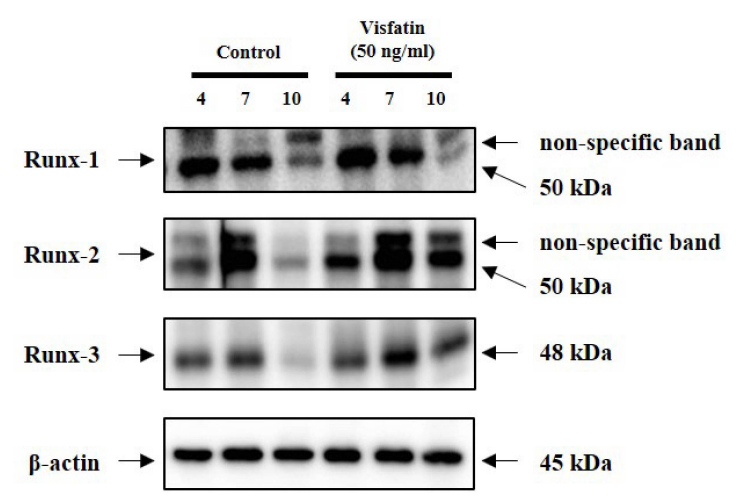

Fig. 5. Analysis of the NAMPT synthesis pathway in MDPC-23 odontoblast differentiation. Western blotting was performed to detect the protein expression levels of Runx-1, Runx-2, and Runx-3 in MDPC-23 cells treated with FK866 (A) or Visfatin (B). $\beta$-Actin served as the experimental control. The expression level of Runx family proteins were assayed using Western blotting. NAMPT, nicotinamide phosphoribosyltransferase; MDPC-23, mouse dental papilla cell-23.

2 and Runx-3 increased as a result of Visfatin treatment (Fig. 5B). These results indicate that NAMPT regulated the differentiation of odontoblasts, and simultaneously regulated Runx signaling, which is involved in extracellular matrix formation.

\section{DISCUSSION}

As an important component of teeth, dentin constitutes most of the crown and root, and synthesizes and secretes organic substrates such as type I and type II collagen, glycoproteins, and DSPP $[20,21]$. As the dentin matrix is deposited, the dentin blast cells form distal cytoplasmic projections, which are buried in the dentinal tubule $[20,21]$. However, little is known of the differentiation mechanism of odontoblasts, or of the factors regulating dentin formation, and the biomolecular mechanisms that are involved. The role of NAMPT in bone formation has recently attracted more attention [22]. NAMPT displayed insulin-like activity as a growth factor for osteoblast cells. The decrease in NAMPT has also been suggested to be associated with age-related fat production [15]. However, there are no published studies on the role of NAMPT in odontogenic differentiation during tooth formation and the molecular mechanisms by which NAMPT promotes odontogenesis. Therefore, in this study, NAMPT and the NAMPT inhibitor, FK866, were applied to the MDPC-23 cell line, which is an odontogenic progenitor cell line derived from mouse dental papilla cells, to reveal the effect of NAMPT on odontoblast differentiation. The characteristic changes in MDPC-23 cells were analyzed. The results showed that NAMPT expression was remarkably up-regulated during MDPC-23 odontoblastic-like cell differentiation (Fig. 1).

Although NAMPT accelerated mineralization in MDPC-23 odontoblastic cells with an associated increase in ALP and Col-1 mRNAs, which are well-known markers of odontoblastic dif- ferentiation [1], NAMPT did not alter the cell viability in MDPC23 cells (Fig. 2). Furthermore, to determine whether NAMPT induced odontogenic differentiation in MDPC-23 cells, we measured the expression levels of DMP-1 and DSPP, a well-known representative marker of odontogenic differentiation $[1,3,23]$. Our qPCR results showed that the expression of DMP-1, DSPP, and NAMPT was gradually up-regulated in MDPC-23 cells treated with Visfatin. Moreover, the expression of the osteogenic differentiation marker gene, BSP, was not observed in MDPC-23 cells. These data indicate that NAMPT may positively accelerate the differentiation of MDPC-23 cells without inducing cell proliferation. FK866 is known to exert antioxidant effects on other oxidative stress-related human diseases, such as viral infections, cardiovascular diseases, and oral mucosal diseases [24]. In contrast, the present results showed that the NAMPT inhibitor FK866 [25] decreased odontoblast formation in MDPC-23 cells (Figs. 3 and 4). While NAMPT accelerated mineralization in MDPC-23 odontoblastic cells, with an increase in the markers of odontoblastic differentiation, namely $A L P, C o l-1, D M P-1$, and $D S P P$, treatment with FK866 did not affect MDPC-23 cell viability (Fig. 3A). Our qRT-PCR and immunoblotting results showed that the expression of DMP-1, DSPP, and NAMPT was gradually down-regulated in MDPC-23 cells treated with FK866. Moreover, the expression of the osteogenic differentiation marker gene, $B S P$, was not observed in MDPC-23 cells. Ling et al. [16], reported that NAMPT is regulating osteoblast differentiation. However, little data have been reported on the role of NAMPT on odontoblast differentiation. Odontoblast is a cell of neural crest origin that is part of the outer surface of the dental pulp [2,3]. Also, the biological function of the odontoblast is the formation of dentin, which is beneath the surface tooth enamel of the crown on the root [4]. Therefore, odontoblast has a significant difference compared to osteoblast. Thus, to confirm the specific odontoblastic cell differentiation, the mRNA and Protein levels of BSP, which is one of the markers 
for bone and cementum specific marker, were accessed by $\mathrm{qPCR}$ and western blot. As shown in Figs. 2C and 4G, NAMPT did not affect the expressional level of BSP in MDPC-23 odontoblast-like cells. Taken together, our data clearly suggest that NAMPT regulates MDPC-23 odontoblasts differentiation.

Runx-1, Runx-2, and Runx-3 of the Runx family, are essential transcription factors that control bone and tooth development by regulating osteoblast and odontoblast differentiation [26]. However, the function of Runx in odontoblast differentiation is unclear. In the present study, NAMPT regulated the differentiation of odontoblasts and simultaneously regulated Runx signaling, which is involved in extracellular matrix formation (Fig. 5). Treatment with FK866 decreased the expression of Runx-1 and Runx-3. However, Visfatin treatment only had a significant effect on the expression of Runx-3, which was increased, whereas the expression of Run-1 was unaffected. These results suggest that Runx-1 and Runx-3 are regulated by NAMPT. The expression of Runx-3 in odontoblasts is particularly interesting because odontoblasts deposit dentin, a hard tissue resembling bone [27]. Interestingly, NAMPT effectively regulated the expression of Runx2 in our study (Fig. 5). Runx-2 is a master transcription factor in bone and plays a role in all stages of bone formation. It is essential for the initial commitment of mesenchymal cells to the osteoblastic lineage and to control the proliferation, differentiation, and maintenance of these cells [27-30]. Runx-2 is also essential for the later stages of tooth formation, is intimately involved in the development of calcified tooth tissue, and exerts an influence on the proliferation of the dental lamina. Furthermore, Runx-2 regulates the alveolar remodeling process that is essential for tooth eruption, and may play a role in the maintenance of the periodontal ligament [29]. Our results suggest that NAMPT plays an essential role as a homeostatic maintenance regulator in odontoblast differentiation. In addition, the increase in NAMPT expression in odontoblasts is closely related to the formation of the extracellular matrix and dentin through the Runx signaling pathway.

In this study, we found that the expression of NAMPT increased significantly during the differentiation of mouse odontoblast-like MDPC-23 cells to odontoblasts. Furthermore, the increase in exogenous NAMPT promoted odontoblastic differentiation and accelerated mineralization without proliferation through an increase in representative odontoblastic biomarkers in MDPC-23 cells. In contrast, the NAMPT inhibitor, FK866, decreased odontoblastic differentiation through the suppression of odontoblastic biomarkers. We also confirmed that the increase in NAMPT expression in odontoblasts is closely related to the formation of the extracellular matrix and dentin via the Runx signaling pathway. Therefore, these data suggest that NAMPT is a critical regulator of odontoblast differentiation during tooth development.

\section{FUNDING}

This research was supported by the Basic Science Research Program through the National Research Foundation of Korea (NRF) funded by the Ministry of Education (NRF-2019R1I1A3A03040819). This study was supported in part by research funds from the Education and Cultural Foundation of the College of Dentistry, Chosun University, 2021.

\section{ACKNOWLEDGEMENTS}

The authors thank Dr. J. E. Nör for supplying the MDPC-23 cells.

\section{CONFLICTS OF INTEREST}

The authors declare no conflicts of interest.

\section{REFERENCES}

1. Lee DS, Yoon WJ, Cho ES, Kim HJ, Gronostajski RM, Cho MI, Park JC. Crosstalk between nuclear factor I-C and transforming growth factor- $\beta 1$ signaling regulates odontoblast differentiation and homeostasis. PLoS One. 2011;6:e29160.

2. Ruch JV. Odontoblast commitment and differentiation. Biochem Cell Biol. 1998;76:923-938.

3. Tummers M, Thesleff I. The importance of signal pathway modulation in all aspects of tooth development. J Exp Zool B Mol Dev Evol. 2009;312B:309-319.

4. Mina M, Kollar EJ. The induction of odontogenesis in non-dental mesenchyme combined with early murine mandibular arch epithelium. Arch Oral Biol. 1987;32:123-127.

5. Sun Q, Liu H, Lin H, Yuan G, Zhang L, Chen Z. MicroRNA-338-3p promotes differentiation of mDPC6T into odontoblast-like cells by targeting Runx2. Mol Cell Biochem. 2013;377:143-149.

6. Park MG, Kim JS, Park SY, Lee SA, Kim HJ, Kim CS, Kim JS, Chun HS, Park JC, Kim DK. MicroRNA-27 promotes the differentiation of odontoblastic cell by targeting APC and activating Wnt/ $\beta$-catenin signaling. Gene. 2014;538:266-272.

7. Telles PD, Hanks CT, Machado MA, Nör JE. Lipoteichoic acid upregulates VEGF expression in macrophages and pulp cells. J Dent Res. 2003;82:466-470.

8. Ritchie HH, Ritchie DG, Wang LH. Six decades of dentinogenesis research. Historical and prospective views on phosphophoryn and dentin sialoprotein. Eur J Oral Sci. 1998;106 Suppl 1:211-220.

9. Tziafas D, Kolokuris I. Inductive influences of demineralized dentin and bone matrix on pulp cells: an approach of secondary dentinogenesis. J Dent Res. 1990;69:75-81.

10. Tziafas D, Papadimitriou S. Role of exogenous TGF-beta in induction of reparative dentinogenesis in vivo. Eur J Oral Sci. 1998;106 Suppl 1:192-196.

11. Narayanan K, Srinivas R, Ramachandran A, Hao J, Quinn B, 
George A. Differentiation of embryonic mesenchymal cells to odontoblast-like cells by overexpression of dentin matrix protein 1. Proc Natl Acad Sci U S A. 2001;98:4516-4521.

12. Sreenath T, Thyagarajan T, Hall B, Longenecker G, D'Souza R, Hong S, Wright JT, MacDougall M, Sauk J, Kulkarni AB. Dentin sialophosphoprotein knockout mouse teeth display widened predentin zone and develop defective dentin mineralization similar to human dentinogenesis imperfecta type III. J Biol Chem. 2003;278:2487424880 .

13. About I, Bottero MJ, de Denato P, Camps J, Franquin JC, Mitsiadis TA. Human dentin production in vitro. Exp Cell Res. 2000;258:3341.

14. Revollo JR, Grimm AA, Imai S. The NAD biosynthesis pathway mediated by nicotinamide phosphoribosyltransferase regulates Sir2 activity in mammalian cells. J Biol Chem. 2004;279:50754-50763.

15. Li Y, He X, Li Y, He J, Anderstam B, Andersson G, Lindgren U. Nicotinamide phosphoribosyltransferase (Nampt) affects the lineage fate determination of mesenchymal stem cells: a possible cause for reduced osteogenesis and increased adipogenesis in older individuals. J Bone Miner Res. 2011;26:2656-2664.

16. Ling M, Huang P, Islam S, Heruth DP, Li X, Zhang LQ, Li DY, Hu Z, Ye SQ. Epigenetic regulation of Runx2 transcription and osteoblast differentiation by nicotinamide phosphoribosyltransferase. Cell Biosci. 2017;7:27.

17. Hanks CT, Fang D, Sun Z, Edwards CA, Butler WT. Dentin-specific proteins in MDPC-23 cell line. Eur J Oral Sci. 1998;106 Suppl 1:260266.

18. Hanks CT, Sun ZL, Fang DN, Edwards CA, Wataha JC, Ritchie HH, Butler WT. Cloned 3T6 cell line from CD-1 mouse fetal molar dental papillae. Connect Tissue Res. 1998;37:233-249.

19. Sun ZL, Fang DN, Wu XY, Ritchie HH, Bègue-Kirn C, Wataha JC, Hanks CT, Butler WT. Expression of dentin sialoprotein (DSP) and other molecular determinants by a new cell line from dental papillae, MDPC-23. Connect Tissue Res. 1998;37:251-261.

20. Bosshardt DD, Nanci A. Hertwig's epithelial root sheath, enamel matrix proteins, and initiation of cementogenesis in porcine teeth. $J$
Clin Periodontol. 2004;31:184-192.

21. Bègue-Kirn C, Smith AJ, Loriot M, Kupferle C, Ruch JV, Lesot H. Comparative analysis of TGF beta s, BMPs, IGF1, msxs, fibronectin, osteonectin and bone sialoprotein gene expression during normal and in vitro-induced odontoblast differentiation. Int J Dev Biol. 1994;38:405-420.

22. Xie H, Tang SY, Luo XH, Huang J, Cui RR, Yuan LQ, Zhou HD, Wu XP, Liao EY. Insulin-like effects of visfatin on human osteoblasts. Calcif Tissue Int. 2007;80:201-210.

23. Gong Q, Wang R, Jiang H, Lin Z, Ling J. Alteration of microRNA expression of human dental pulp cells during odontogenic differentiation. JEndod. 2012;38:1348-1354.

24. Ok CY, Park S, Jang HO, Takata T, Lee OH, Bae MK, Bae SK. FK866 protects human dental pulp cells against oxidative stress-induced cellular senescence. Antioxidants (Basel). 2021;10:271.

25. Travelli C, Aprile S, Rahimian R, Grolla AA, Rogati F, Bertolotti M, Malagnino F, di Paola R, Impellizzeri D, Fusco R, Mercalli V, Massarotti A, Stortini G, Terrazzino S, Del Grosso E, Fakhfouri G, Troiani MP, Alisi MA, Grosa G, Sorba G, et al. Identification of novel triazole-based nicotinamide phosphoribosyltransferase (NAMPT) inhibitors endowed with antiproliferative and antiinflammatory activity. J Med Chem. 2017;60:1768-1792.

26. Li S, Kong H, Yao N, Yu Q, Wang P, Lin Y, Wang J, Kuang R, Zhao $\mathrm{X}, \mathrm{Xu}$ J, Zhu Q, Ni L. The role of runt-related transcription factor 2 (Runx2) in the late stage of odontoblast differentiation and dentin formation. Biochem Biophys Res Commun. 2011;410:698-704.

27. Yamashiro T, Aberg T, Levanon D, Groner Y, Thesleff I. Expression of Runx1, -2 and -3 during tooth, palate and craniofacial bone development. Gene Expr Patterns. 2002;2:109-112.

28. Camilleri S, McDonald F. Runx2 and dental development. Eur J Oral Sci. 2006;114:361-373.

29. Wen Q, Jing J, Han X, Feng J, Yuan Y, Ma Y, Chen S, Ho TV, Chai Y. Runx2 regulates mouse tooth root development via activation of WNT inhibitor NOTUM. J Bone Miner Res. 2020;35:2252-2264.

30. Marie PJ. Transcription factors controlling osteoblastogenesis. Arch Biochem Biophys. 2008;473:98-105. 